\title{
O NOVO PARADIGMA DOS PRECEDENTES JUDICIAIS NO NOVO CODIGO DE
} PROCESSO CIVIL

Thais Gomes da Silva, Rachel Lopes Queiroz Chacur

Universidade do Oeste Paulista - UNOESTE, curso de Direito, Presidente Prudente, SP. Email: thaisgomessilva46@gmail.com

\section{RESUMO}

O presente projeto de pesquisa analisará um novo modelo de Teoria dos Precedentes Judiciais, no Brasil. Inicialmente, abordaremos distinção de dois sistemas jurídicos ou modelos processuais dominantes denominados "civil law" e "common law", após a operacionalização dos mesmos em cada sistema.

Palavras-chave: Novo CPC, alterações, Precedente judiciais, comparação, CPC/73.

\section{THE NEW PARADIGM OF PREVIOUS COURT IN THE NEW CIVIL PROCEDURE CODE}

\section{ABSTRACT}

This research project will analyze a new model of Theory of Judicial Precedent in Brazil. Initially, we discuss distinction of two legal systems and procedural models called dominant civil law and common law, after the implementation of the same on each system.

Keywords: New CPC, changes, judicial precedent, comparison, CPC / 73. 


\section{INTRODUÇÃO}

O Novo Código de Processo Civil ao tratar da nova Teoria dos Precedentes Judiciais compara os sistemas jurídicos dominantes nos ordenamento jurídicos internacionais, assim denominados "civil law" e "common law". Ocorre que, há discussão sobre a adoção desse sistema hibrido ou novo sistema de julgamento e vinculação de decisões judiciais no ordenamento jurídico brasileiro, bem como a sua operacionalização nos Tribunais, do país.

Para tanto, é necessária a apresentação desses novos conceitos fundamentais para a operação com precedentes como os de ratio decidendi e obter dictum, os quais justificam a origem etimológica do instituto processual.

Entretanto, as questões teóricas também merecem uma análise e um estudo de operacionalização perante o 1으 Grau e 2ㅇ Grau, sobre a aplicabilidade desses precedentes judiciais.

Se o instituto do Precedente Judicial versa sobre uma otimização dos mecanismos recursais no modelo processual brasileiro.

Para tal, far-se-à necessário comprovar se essa é a forma mais adequada de valorização da jurisprudência e se a mesma gerará efetividade ao processo e a tutela jurisdicional.

Em síntese, se a adoção do instituto de Precedentes Judiciais manterão as garantias constitucionais e versarão sobre tão somente um instrumento de racionalização do sistema judicial.

\section{METODOLOGIA}

Os materiais e métodos utilizados para o projeto de pesquisa em desenvolvimento são os materiais Permanentes e de Consumo.

Os Métodos de Abordagem serão o Método dedutivo e indutivo. Para o desenvolvimento metodológico da pesquisa utilizamos o levantamento do referencial bibliográfico, legislativo e pareceres de Comissões próprias.

De acordo com esta proposta inicial do projeto, o próximo passo de coleta de dados, utilizaremos os dados à serem analisados quanti-qualitativamente, considerando-se que há uma relação dinâmica e indissociável entre o mundo objetivo e a subjetividade do sujeito que não pode ser traduzida somente em números.

$\mathrm{Na}$ área jurídica primamos pela análise lógico-racional utilizada nas interpretações literais e semânticas da norma processual, sua eficácia e efeitos e os reflexos na rotina forense; lembrando 
que todos os dados são de domínio público, pois constam de páginas oficiais ou artigos científicos abertos à comunidade acadêmica e sociedade, em geral.

\section{OS RESULTADOS PARCIAIS}

O Novo Código de Processo Civil trouxe significativas alterações no novo instituto do Precedente Judicial, levando em conta a mudança de paradigma do sistema positivado do "civil law", para uma concepção próxima ao sistema do "como law", em que legislador previu a formação de precedentes judiciais, por causa pilotos e idênticas, com a finalidade de uniformização das decisões judiciais de natureza repetitiva, perante os órgãos judiciais brasileiros. O desenvolvimento inicial do projeto de pesquisa demonstrou que há uma ruptura de paradigma de um modelo de decisão judicial pautada em um sistema positivado, com a utilização de um sistema de uniformização da jurisprudência paras as causas repetitivas, no sentido de otimizar os serviços prestados pelos Tribunais Superiores, no Brasil. Contudo, restam-nos a indagação sobre os limites impostos a garantia constitucional do "Principio da Inafastabilidade do Poder Judiciário", a provável minimização do Acesso à Justiça frente a necessária racionalização do sistema estrutura do Poder Judiciário.

\section{REVISÃO DE LITERATURA}

Com a revisão do novo CPC vem sendo discutido a implantação do uso de precedentes judiciais como fonte do direito ao sistema jurídico brasileiro, que atualmente utiliza-se do civil law, ou seja, a lei como fonte primaria. Até que ponto este sistema jurídico será eficaz e não ferirá os princípios constitucionais do direito processual, afetando a inercia e imparcialidade do juiz diante das decisões proferidas.

É importante conhecer os dois sistemas jurídicos, principalmente pelo destaque que vem ganhando em nosso ordenamento jurídico, revelado pela eficácia que o legislador brasileiro vem emprestando ao precedente judicial, como dito por Diddier (2012).

O presente estudo tem como objetivo identificar os dois sistemas jurídicos predominantes: o "civil law" e "common law", caracterizando-os e esclarecendo a importância de cada um como fonte do Direito. De outro lado, o debate enfoca questões à respeito da utilização dos precedentes judiciais no sistema jurídico brasileiro confrontando diretamente com os Princípios Gerais do direito processual expressos, em nossa Constituição Federal; os quais resultam também em conotações éticas, sociais e politicas ao andamento dos processos. 
As apresentadas características fundamentais dos dois sistemas "civil law" e "common law", origem, técnicas para interpretação e compreensão dos fatos e fundamento jurídicos do caso em concreto levam ao apelo às vantagens e desvantagens da utilização destes precedentes judiciais, no sistema jurídico brasileiro.

Àqueles que são contrários a adoção do sistema "common law" justificam um confronto com os Princípios Fundamentais Constitucionais expressos na Constituição Federal, os quais dão direcionamento ao sistema processual atual do Brasil.

Ora, o fator preponderante de discussão é a transição de um modelo positivado e limitado para um sistema hibrido, não diríamos um modelo típico do sistema "comow law"; denominados para alguns juristas como o sistema "cover" de adaptação no julgamento, formação e decisão final dos precedentes judiciais.

O presente trabalho merece o aprofundamento teórico sobre Precedente Judiciais durante todo o trâmite do desenvolvimento do projeto de pesquisa, para desmistificar os erros e acertos da escolha por esse novo instituto dos Precedentes Judiciais, indicando naquilo que avançará à contento para a otimização do sistema recursal brasileiro e, por outro lado, sem olvidar as Garantias Constitucionais previstas na Constituição Federal de 1988.

\section{O sistema jurídico Common Law}

\subsection{0 que é?}

É um termo utilizado para se referir a um sistema cuja aplicação das normas não estão escritas, mas sancionadas pelo costume (SANTIAGO, 2014). As lides são resolvidas tomando-se com base nas decisões proferidas anteriormente, que são transformadas em orientações para o julgamento de casos análogos. Nesse sistema, quando não existe um precedente, os juízes possuem a autoridade para criar o direito, formando um precedente que irá vincular as decisões futuras.

\subsection{Origem}

Formado pela teoria stare decisis (mantenha-se a decisão e não se moleste o que foi decidido), onde utiliza-se o precedente judicial como fonte de lei. As decisões possuem efeito vinculante para todos os juízos. Teve inicio na Inglaterra, "reconhecida em 1898 no caso London Tramways Company v.London County Council, onde a Câmara dos Lordes inglesa não só tratou do efeito auto-vinculante do precedente como também estabeleceu a sua eficácia vinculativa 
externa a todos os juízos de grau inferior, chamada de eficácia vertical do precedente"(TUCCI, 2001).

\section{O sistema jurídico Civil law}

\subsection{O que é?}

É o sistema jurídico em que a fonte primaria do direito é a Lei. È o direito escrito, ou conforme descrito por Montesquieu "o juiz é a boca da lei", prevalecendo a vontade soberana do Estado, buscando-se a segurança jurídica.

\section{$2.2 \quad$ Origem}

Teve origem nos países herdeiros da família romano-germânica (Itália, França, Alemanha, Espanha e em Portugal, e toda América Latina colonizada por portugueses e Espanhóis).

\section{A utilização de precedentes judiciais no Brasil}

Como já visto, precedente judicial é a decisão proferida através de um caso concreto já julgado, que serve como diretriz para julgar questões posteriores análogas.

Com ou aumento excessivo da demanda de processos nos tribunais, vem-se buscando uma forma de resolver tal crise oferecendo aos magistrados uma maior autonomia para julgar os casos porem sem perder a segurança jurídica, isonomia, entre outros.

O sistema brasileiro já adota o precedente vinculante desde 1993, quando foi inserido o paragrafo 2ำ ao artigo 102 da Constituição Federal:

As decisões definitivas de mérito, proferidas pelo Supremo Tribunal Federal, nas ações diretas de inconstitucionalidade produzirão eficácia contra todos e efeito vinculante, relativamente aos demais órgãos do Poder Judiciário e à administração publica direta e indireta, nas esferas federal, estadual e municipal.

Assim, José Rogerio Cruz e Tucci (2011) afirma que os precedentes judiciais constituem também uma fonte de direito, dentro dos sistemas jurídicos da tradição civil law.

\section{A utilização da jurisprudência como fonte do direito \\ Uma das discussões quanto a utilização dos precedentes judiciais é saber se a} jurisprudência pode ser considerado fonte do direito. José Guilherme de Souza (1991, p-35) 
“existe um consenso, cada vez mais sedimentado, no sentido de admitir-se que a jurisprudência é fonte do direito".

A lei vem perdendo sua posição central como fonte do direito e passou a ser subordinada a Constituição, não valendo por si só, mas somente se conformada e adequada aos direitos fundamentais. A função dos magistrados passou de ser apenas declarar a vontade concreta da lei, e passou a assumir o caráter constitucional possibilitando o controle da constitucionalidade das leis o dos atos normativos (LOURENÇO, 2011).

Segundo o autor (DIDIER, 2012) diz que "a jurisdição é uma atividade criativa da norma jurídica do caso concreto, bem como se cria, muitas vezes, a própria regra abstrata que deve regular o caso concreto". Deve-se abandonar a ideia de que o Poder Judiciário só exerce a função de legislador Negativo.

A atividade criativa do juiz pode se dar de duas maneiras, sendo a primeira no sentido de criar a norma jurídica do caso concreto; e a segunda, a norma geral do caso jurídico, pelo qual, o juiz deverá demonstrar a norma geral do ordenamento jurídico, que soluciona o caso concreto (não apenas a lei em si, mas o entendimento do juiz acerca dessa lei).

Logo, a norma geral do caso concreto é a interpretação feita pelo juiz, do direito positivo. As normas gerais criadas a partir de casos concretos estão na fundamentação das decisões e se configuram como aquilo que se chama precedente judicial, que é exatamente a norma geral criada a partir do caso concreto (LOURENÇO; HAROLDO, 2011).

Tendo em vista, essa nova dinâmica de decisão, interpretação e resolução do processo. Denota-se a necessidade de avaliar essa transição de novos modelos e cultura jurídica, à partir da utilização dos Precedentes Judiciais, com o Novo Código de Processo Civil.

\section{CONCLUSÃO}

O presente projeto de pesquisa em desenvolvimento aborda a mudança de Paradigmas no Sistema Recursal no Novo Código de Processo Civil, naquilo concernente a eficácia dos julgamentos de 1 ㅇ e 20 Grau, seus procedimentos e seus efeitos no plano prático forense.

A adoção do Sistema de Precedentes Recursais pelo Novo Código de Processo Civil poderá trazer uma alteração na cultura jurídica de minimização de interposição de recursos no 10 e 2o Grau de Jurisdição, bem como uma nova dinâmica no procedimento recursal, considerando uma uniformização dos julgamentos dos Tribunais Superiores, para obtenção de um entendimento jurídico que propicie uma maior segurança jurídica das relações sociais. 
Contudo, resta-nos avaliar a implementação desta nova sistemática face à ruptura de um paradigma de amplo espectro de reexame nos Tribunais, para uma concepção reducionista de acessos pelas vias recursais.

Cumpre a Ciência Jurídica e a prática forense constatar a adoção, deste novo sistema.

\section{REFERÊNCIAS}

ATAÍDE JÚNIOR, Jaldemiro Rodrigues de. Precedentes vinculantes e irretroatividade do direito no sistema processual brasileiro: os precedentes dos tribunais superiores e sua eficácia temporal. Curitiba: Juruá, 2012.

DIDIER JR., Fredie. Curso de Direito Processual Civil. V. II. 7. ed.,JusPodium, 2012.

FILIPPO, Thiago Baldani Gomes de. Adoção de um sistema de precedentes no Brasil como reflexo da atual ordem constitucional. Disponível em http://jus.com.br/revista/texto/13487/adocao-deum-sistema-de-precedentes-no-brasil-como-reflexo-da-atual-ordem-constitucional Acesso em 13 de maio de 2012.

LEITE, Gisele; HEUSELER, Denise. Commun law à brasileira. Disponível em http://jus.com.br/revista/texto/20262/common-law-a-brasileira Acesso em 15 de maio de 2012.

MACEDO, Gabriela Silva. A eficácia vinculante do precedente judicial no Direito brasileiro e sua importância para atuação do Poder Judiciário. Disponível em http://jus.com.br/revista/texto/21528/a-eficacia-vinculante-do-precedente-judicial-no-direitobrasileiro-e-sua-importancia-para-atuacao-do-poder-judiciario Acesso em 13 de maio de 2012.

MARINONI, Luiz Guilherme. Precedentes Obrigatórios. 2.ed. rev. e atual. São Paulo: Editora Revista dos Tribunais, 2011.

MELLO, Patrícia Perrone Campos. Precedentes: o desenvolvimento judicial do direito no constitucionalismo contemporâneo. Rio de janeiro: Renovar, 2008.

$\mathrm{ClANCl}$, Mirna. Súmula vinculante. Os meios processuais de controle da vinculação (Lei 11.417/2006, art. 7.). Direito Civil e Processo - Estudos em homenagem ao Professor Arruda Alvim. São Paulo: Revista dos Tribunais, 2008. Org. Assis, A. de; Arruda Alvim, E. P. de; Nery Jr., N.; Mazzei, R. R.; Arruda Alvim Wambier, T.; Arruda Alvim, T. C. D. de.

NUNES, Dierle. Precedentes, padronização decisória preventiva e coletivização - Paradoxos do sistema jurídico brasileiro: uma abordagem constitucional democrática, Direito Jurisprudencial, São Paulo: Revista dos Tribunais, 2012. Coord. Tereza Arruda Alvim Wambier.

LOURENÇO; HAROLDO. 2011. PRECEDENTE JUDICIAL COMO FONTE DO DIREITO: ALGUMAS CONSIDERAÇÕES SOB A ÓTICA DO NOVO CPC, ano 2014.

SOUZA, Marcelo Alves Dias de. Do precedente judicial à súmula vinculante. 1.ed. (ano 2006), 5. reimp. Curitiba: Juruá, 2011. 
TARANTO, Caio Mário Guetterres. Precedente Judicial: Autoridade e Aplicação na Jurisdição Constitucional. Rio de janeiro: Editora Forense, 2009.

TEIXEIRA, Sálvio de Figueredo. A súmula e a sua evolução no Brasil. Biblioteca Digital Jurídica do Superior Tribunal de Justiça. Disponível em http://bdjur.stj.jus.br/xmlui/bitstream/handle/2011/2083/S\%c3\%bamula_Evolu\%c3\%a7\%c3\%a3o _Brasil.pdf?sequence=4 Acesso em 3 de maio de 2012.

TUCCI, José Rogério Cruz e. Precedente judicial como fonte do Direito. São Paulo: RT, 2011.

TUCCI, José Rogério Cruz e. Precedente judicial como fonte de direito. São Paulo: Revista dos Tribunais, 2004. (Cap. V, p. 119-148).

SANTIAGO, Willis Guerra Filho. Processualização dos Precedentes Judiciais. Processual - RBDPro, Belo Horizonte, ano 22, n. 88, out./dez., 2014.

SOUZA JUNIOR, Fredie Didier, BRAGA, Paula Sarno, OLIVEIRA, Rafael. Curso de Direito Processual Civil, 7. ed. v. 2, Editora Jus Podivum, 2012.

SOUZA, José Guilherme de. A criação judicial do direito. Porto Alegre: SAFE, 1991, p-35.

WAMBIER, Teresa Arruda Alvim; MELLO, Rogério Licastro Torres De; RIBEIRO, Leonardo Ferres da Silva. Primeiros Comentários ao Novo Código de Processo Civil Artigo por Artigo. São Paulo: Editora Revista dos Tribunais, vol.1, 1a ed., 2015

\section{ENUNCIADOS:}

ENUNCIADOS DO III EDIÇÃO DO FÓRUM PERMANENTE DE PROCESSUALISTAS CIVIS, no Rio de Janeiro, R. J., Maio de 2014.

ENUNCIADOS DO IV EDIÇÃO DO FÓRUM PERMANENTE DE PROCESSUALISTAS CIVIS, Belo Horizonte, M. G., Dezembro de 2014.

\section{LEGISLAÇÕES:}

\section{ANTEPROJETO DE LEI E PROJETO DE LEI:}

Lei 5.869/73), PL. 8046 / 2010, Projeto de Lei do Senado 166/2010, entre outros.

BRASIL. Senado. Comissão de Juristas Responsável pela Elaboração de Anteprojeto de Código de Processo Civil. Código de Processo Civil: anteprojeto. Disponível em: <http://www.senado.gov.br/senado/novocpc/pdf/Anteprojeto.pdf>. Acesso em: 02 jul. 2012.

LEI № 6.025, DE 2005 DO CODIGO DE PROCESSO CIVIL, versão da Câmara dos Deputados. Redação Final aprovada em 26 de Março de 2014. 